\title{
Los poderes emergentes en la política internacional de comienzos del siglo XXI: el caso de Brasil como potencia suramericana
}

\author{
Emerging powers in international politics at the beginning of the 21 st century: \\ the case of Brazil as a South American power
}

\begin{abstract}
Marco Cayetano De Benedictis
dictis.marco@gmail.com

Centro de Investigaciones Geográficas - Instituto de Investigaciones en Humanidades y Ciencias Sociales Facultad de Humanidades y Ciencias de la Educación, Universidad Nacional de La Plata, Argentina
\end{abstract}

Recepción: 08 Agosto 2020

Aprobación: 21 Septiembre 2020

Publicación: 03 Mayo 2021

Cita sugerida: De Benedictis, M. C.(2021). Los poderes emergentes en la política internacional de comienzos del siglo XXI: el caso de Brasil como potencia suramericana. Geograficando, 17(1), e091. https://doi.org/10.24215/2346898Xe091

\begin{abstract}
Resumen: En el presente artículo se analizarán los cambios que han llevado a la irrupción de los poderes emergentes en la geopolítica global. Se centrará el análisis en los países BRICS en una primera instancia y luego se enfocará la atención en el caso de Brasil, para comprender cómo este contexto impactó en América del Sur y qué cambios se dan en el contexto actual. Lo que se demostrará es que estos países lograron consolidar su posición internacional a partir de su peso a nivel regional, pero sus objetivos no estaban vinculados a un cambio sistémico de la política global, sino a obtener un lugar de relevancia en las decisiones mundiales.

Palabras clave: Geopolítica, Poderes emergentes, Potencia regional, Brasil.

Abstract: This article will analyze the changes that have led to the inception of emerging powers in global geopolitics. The analysis will focus on the BRICS countries in the first instance and then focus on the case of Brazil, to understand how this context impacted South America and what changes are taking place in the current context. What will be shown is that these countries managed to consolidate their international position based on their weight at the regional level, but their objectives were not linked to a systemic change in global policy, but rather to obtain a place of relevance in world decisions.
\end{abstract}

Keywords: Geopolitics, Emerging powers, Regional power, Brazil.

\section{INTRODUCCIÓN}

Las primeras dos décadas del siglo XXI están marcando un destacable movimiento en las relaciones políticas internacionales a nivel global. Los acontecimientosel fin de la Guerra Fría y el desmembramiento de la Unión de Repúblicas Socialistas Soviéticas (URSS), dieron lugar a un período donde la supremacía global de Estados Unidos parecía única e indiscutible. En calidad de resultar la potencia triunfadora de dicho enfrentamiento con el bloque comunista, se estableció a nivel mundial un consenso en torno a los valores liberales y democráticos representados por los países occidentales, además de su organización 
económica neoliberal. Estos hechos han terminado de consolidar en todo el planeta el proceso de globalización.

Dicho consenso que se creía universal empezó a ser cuestionado a partir del presente siglo por nuevos actores de peso en las relaciones internacionales. Ellos se ubicaban dentro de los que comúnmente se conoce como "poderes emergentes", y entre sus principales premisas se encontraba la crítica al sistema internacional interdependiente heredado de la época posterior a la Segunda Guerra Mundial, pero sin buscar un cambio transformador del mismo.

En el presente artículo se analizarán los cambios que han llevado a la irrupción de estos poderes emergentes en el centro de la escena de la política internacional. Se centrará el análisis en los países BRICS (compuestos por Brasil, Rusia, India, China y Sudáfrica), en una primera instancia, y luego se enfocará la atención en el caso de Brasil, para comprender cómo este contexto impactó en América del Sur y en qué situación se encuentra actualmente. Lo que se demostrará es que estos países lograron consolidar su posición internacional a partir de su peso a nivel regional, pero sus objetivos no estaban vinculados a un cambio sistémico de la política global, sino a obtener un lugar de relevancia en las decisiones económicas y políticas mundiales. Para llegar a estos puntos, se realizará una revisión de diferentes trabajos que abordan esta temática desde una perspectiva cualitativa. Se partirá de un análisis del período posterior al fin de la Guerra Fría, fundamentalmente la última década del siglo XX y los comienzos del siglo XXI, que dieron impulso a este proceso de aparición en las altas esferas internacionales de Estados que hasta el momento no habían tenido ese rol. Luego, se centrará el análisis en el ya mencionado grupo de países BRICS, quienes fueron los que obtuvieron mayor notoriedad, y hasta llegaron a coordinar políticas en común. Para finalizar, se destacará el papel que ha tenido Brasil como poder emergente a nivel global, su consolidación como potencia regional en América del Sur y su actual cambio de rumbo en este plano.

\section{LA Post Guerra Fría Y EL COMIEnZo del SIGLO XXI}

La última década del siglo pasado estuvo atravesada por grandes cambios en la geopolítica a nivel global. Estos cambios estuvieron directamente vinculados al fin de la Guerra Fría. Hay que tener en cuenta que este enfrentamiento, desarrollado entre las dos mayores potencias que resultaron victoriosas de la Segunda Guerra Mundial (Estados Unidos y la URSS) dominó todos los vínculos políticos a internacionales, tanto entre los diferentes Estados, como así también en la participación que actores no estatales pudieran tener en asuntos de índole internacionales (por ejemplo, a través del accionar de Organizaciones No Gubernamentales). Pero la caída del muro de Berlín y la posterior desintegración de la URSS generaron un cambio rotundo. Estados Unidos se posicionó como el único actor hegemónico en el planeta, generando una visión en el resto de los Estados que la validez de su ideología liberal, democrática, centrada en el mercado, era la base de su propia legitimidad. Como señala Domínguez (2015), "para 1991 la Unión Soviética había sido totalmente derrotada. La URSS se fragmentó en las repúblicas que hasta entonces la conformaban y la estructura del sistema internacional se volvió terriblemente asimétrica para beneficio de la coalición encabezada por Estados Unidos” (p. 393). Incluso parte del exbloque soviético se terminó acoplando a los intereses de Occidente, cuando la mayoría de los Estados que habían formado parte del Pacto de Varsovia ingresaron en la Unión Europea en el 2004, gracias a su expansión hacia el este europeo.

Como se ha mencionado, este proceso se vivió en todo el mundo, por lo cual el continente americano no estuvo exento del mismo. La década de 1990 marcó una época también de consenso democrático liberal. Una muestra palpable de esto fue la retirada de Estados Unidos de su postura a lo largo de la Guerra Fría, donde su intervención militar (directa o indirectamente) en el territorio latinoamericano se hizo recurrente. La posición hegemónica estadounidense se consolidó no sólo desde el ámbito político y militar, sino también desde el punto de vista de su modelo de desarrollo económico. La firma del Tratado de Libre Comercio de América del Norte (TLCAN), la conformación del Mercosur, como un territorio a partir del cual proyectar 
a sus países a los mercados internacionales, y el impulso que se le dio a la conformación del Área de Libre Comercio de las Américas (ALCA) dan cuenta de esto. Siguiendo lo planteado por el ya citado Domínguez,

una década después de la caída de la Unión Soviética, la primacía de Estados Unidos prácticamente no era cuestionada, el consenso ideológico y las políticas democrático-liberales y orientadas al mercado seguían siendo dominantes, y la acción colectiva en el continente americano se mantenía como norma eficazmente aplicada (2015, p. 401).

De esta manera, se estableció lo que Rocha y Morales (2008) denominaron como "neoparamericanismo". Mediante este concepto, estos autores destacaban que el sistema interamericano de relaciones entre los Estados, creado durante la segunda mitad del siglo XX, había entrado en una crisis con el fin de la Guerra Fría. Esto llevó a una paulatina reestructuración en tres ejes principales: uno económico (apuntado a la creación del mencionado ALCA), otro político (mediante la reforma de la Organización de Estados Americanos, OEA) y uno militar (a través de la superación del Tratado Interamericano de Asistencia Recíproca, TIAR). Como señalan los autores mencionados previamente, la potencia norteamericana buscaba "redefinir su hegemonía en el hemisferio a partir de tres ideas fundamentales: libre comercio (...), democracia representativa (...) y seguridad hemisférica" (2008, p. 53). Todo este sistema se estableció bajo la cobertura ideológica neoliberal del Consenso de Washington.

Este consenso de fin de siglo pasado se vio alterado al comenzar el nuevo milenio. Una de las causas de este cambio fue el rumbo tomado por la administración de George W. Bush luego del atentado a las Torres Gemelas del 11 de septiembre de 2001. Este acontecimiento legitimó el proyecto neoconservador que tenían los republicanos para su política internacional. Esto incluía relegar el avance en el multilateralismo que había plasmado el gobierno de Clinton durante la década de los noventa. La política exterior, entonces, se basaba en el unilateralismo y la unipolaridad, con eje fundamental en la seguridad. Si bien durante el segundo mandato de Bush (2004-2008) algunos aspectos cambiaron (como la incorporación de una visión multilateral en cuestiones comerciales) la imagen de Estados Unidos como la gran potencia hegemónica comenzaba a ser puesta en discusión. Más allá de que su lugar como principal superpotencia aún no llega a ponerse en discusión, se ha erosionado su posición hegemónica.

Finalmente, se sumaron otros factores en el escenario internacional que permitieron la aparición cada vez más destacable de otros países. Además del ya mencionado desgaste del modelo hegemónico unilateral de Estados Unidos, también se registraron cambios en los flujos comerciales (tomando gran relevancia los vínculos Este-Sur) y una mayor participación de países periféricos y semiperiféricos en las cadenas globales de valor permitiéndoles mejorar sus situaciones económicas. Como destaca la Organización Mundial de Comercio (2013), la participación en las exportaciones mundiales de mercancías de territorios considerados como en desarrollo o emergentes pasó de ser del $34 \%$ en el año 1980 a un $47 \%$ en el 2011, marcando un significativo aumento. El caso más significativo sucedió en China, donde en dicho período de treinta años pasó de un insignificante $1 \%$ al $11 \%$. Por su parte, para el mismo período, el peso de las economías desarrolladas bajó desde un $66 \%$ hasta un $53 \%$.

Esto se complementó con un comienzo de siglo XXI sin un consenso general que marcara las acciones de las instituciones multilaterales (como lo fue el Consenso de Washington durante los noventa). En este contexto, los nuevos actores que comenzaron a tener mayor relevancia mundial fueron los países considerados como potencias emergentes.

\section{LA IRRUPCión DE LOS PODERES EMERGENTES. EL CASO DE LOS BRICS}

Con este contexto de una cierta pérdida de la hegemonía unilateral de los Estados Unidos en la política global, aparecieron nuevos actores en dicho escenario. Estos nuevos actores se caracterizaron como "poderes emergentes", ya que no formaban parte del grupo de países desarrollados que habían sido parte del centro de la gobernanza global. Se han desarrollado muchas conceptualizaciones de dicho término, de modo que a 
continuación se presentarán algunas características generales que ayuden a comprender de qué tipo de países se trata.

Uno de los puntos de vista más utilizados para reconocer a los poderes emergentes tiene que ver con variables económicas, ya que se trata de las zonas más dinámicas de crecimiento del mundo. No obstante, este indicador es volátil e insuficiente, debido a que varios de los países considerados emergentes se han visto alterados por los vaivenes en los valores internacionales de los productos en los que especializan sus exportaciones y se han generado altibajos también en su propio desarrollo. Por este motivo, Giaccaglia propone otorgar un enfoque más integral al concepto de poder emergente "incluyendo no sólo aspectos económicos, sino también elementos vinculados a la política doméstica y a la proyección internacional de un determinado país" (2017, p. 430).

Esta misma autora destaca que la idea de caracterizar a algunos Estados como "poderes emergentes" proviene de la categoría de potencia media que se utilizaba durante el período de la Guerra Fría. Esta noción se utilizaba para destacar a países que se encontraban bajo la esfera de influencia norteamericana, y cumplían con dos funciones específicas: por un lado, articulando nuevas ideas y negociando temas en los cuales las superpotencias no tenían interés directo; por el otro, moderando tensiones entre el Este-Oeste buscando consensos dentro de Naciones Unidas. Este concepto se amplió en los setenta con la aparición de nuevas potencias medias, también reconocidas como potencias regionales, por su peso demográfico, económico y militar y su consolidación de espacios de influencia regional (dentro de esta categoría se incluían una gran variedad de países, como India, México y Brasil, entre otros). Estas nuevas potencias medias tenían la particularidad de tener una doble actuación, ya que además de su influencia regional, podían desenvolverse en ámbitos globales.

El concepto desarrollado por Giaccaglia de poder medio emergente, entonces, hace referencia a

aquel Estado que sobre la base de significativas capacidades materiales desarrolla un creciente activismo internacional en ámbitos multilaterales (...). Asimismo, se autopercibe y es percibido por otros agentes como diferente tanto de las restantes unidades estatales (pequeñas o grandes), como de las grandes potencias tradicionales (2017, p. 433).

De esta manera, los poderes emergentes se caracterizan por tres dimensiones diferentes. En primer lugar, sus capacidades materiales, tanto en términos militares (su posibilidad de controlar su territorio) como económicas (su desarrollo productivo, basado en la dotación de recursos naturales y humanos, y su participación en la economía global). En segundo lugar, su activismo internacional, sustentado en la participación en organismos internacionales. Y, en tercer lugar, las percepciones propias y ajenas, es decir la forma en la que el país es considerado por otros actores.

En una línea semejante, Morales (2013) se enmarca en las teorías del sistema-mundo para destacar que el papel de potencias emergentes ha sido ocupado por países que el autor ubica en la semiperiferia. Él desarrolla una serie de características de estos países para comprender su función dentro de las relaciones internacionales, ya que los considera un elemento estructural necesario en la economía-mundo:

- En primer término, señala que se trata de Estados en una situación intermedia en el sistema interestatal-internacional entre el centro y la periferia. Esta posición no tiene que ver exclusivamente con la división internacional del trabajo, sino también con una función geoeconómica y geopolítica y en el sistema interestatal-internacional.

- En segundo lugar, las economías semiperiféricas introducen nuevas mercancías, nuevas fuentes de energía, nuevos métodos de producción y organización, reproduciendo desarrollos previos, es decir que no generan su propia innovación. Están insertos dentro de las cadenas globales de valor, forman parte de ellas, pero no logran acceder a las rentas más lucrativas. Así, presentan una relación de dependencia con las potencias centrales, mediante las inversiones extranjeras, pero tienen una posición de dominación sobre las periferias. Otro punto interesante de sus características económicas es que tienen participación en todo tipo de industrias, aunque sin ser vanguardia en ninguna de ellas ni 
controlar los sectores de las cadenas productivas con mayores ganancias. Los ingresos de su población y sus niveles de consumo promedian un nivel medio, aunque con una distribución muy desigual.

- Presentan aparatos estatales en proceso de modernización. Los aparatos estatales de la semiperiferia centran su interés en el control económico y social. Estos países tienden a emplear políticas de desarrollo dirigidas y movilizadas por el Estado, en mayor medida que en países centrales y periféricos.

- Las sociedades semiperiféricas presentan una gran desigualdad. Coexisten sectores con un bienestar comparable al de los países centrales, con otros sectores de extrema precariedad y rezago. Además, existen grandes disparidades de desarrollo y bienestar en diferentes regiones geográficas al interior de cada Estado semiperiférico.

- Estas mismas sociedades son puntos de encuentro y discordancia entre fuerzas sociales centralizantes y periferizantes. Estos países resultan espacios atractivos para migrantes tanto del centro como de la periferia.

- La posición intermedia de la semiperiferia es una postura política. Los Estados centrales buscan garantizar que el desarrollo político, militar y económico de los semiperiféricos no afecte sus intereses locales, regionales y mundiales. Por su parte, ellos cuentan con

mercados nacionales amplios y dinámicos, extensiones territoriales suficientes, ejércitos populosos y niveles de intercambio comercial considerables. Esto les permite (...) trazar proyectos de articulación de infraestructura dentro y fuera de sus fronteras, esbozar idearios socio-culturales en espacios regionales, ejercer liderazgo y eventualmente supremacía entre sus vecinos, impulsar sistemas de integración y desplegar una política exterior proactiva en defensa de los intereses regionales (Morales, 2013, p. 160)

Por esta razón, los países centrales suelen intentar coaptarlos y reducir su influencia regional y global.

- Por último, la semiperiferia no representa una posición fija, sino un punto de ascenso y/o descenso de los países. Esto se debe a que se trata de la zona más dinámica de tránsito, interconexión y flujo en el sistema-mundo. Así, la semiperiferia es influenciada por procesos centrales como así también por procesos periféricos. De esta manera, algunos Estados semiperiféricos pueden ser impulsados hacia el centro, o bien pueden ser frenados y arrastrados hacia la periferia.

De esta forma, tanto el concepto de poderes emergentes como el de semiperiferia involucran al mismo grupo de países, que son aquellos que se destacan en determinado momento histórico, despegándose tanto de las potencias centrales como así también de los países periféricos.

A comienzos del siglo XXI, dentro de una amplia gama de países que se destacan como poderes emergentes, el grupo que más impacto ha tenido a nivel global es el denominado BRICS, por las iniciales de los cinco países que lo conforman: Brasil, Rusia, India, China y Sudáfrica. Estos son los países que, en las últimas dos décadas, han desarrollado los procesos de ascenso estructural más acelerados y profundos.

El término BRIC fue creado en 2001 por Jim O 'Neill, de la consultora Goldman Sachs, para designar al grupo de países emergentes con potencial de liderazgo económico en los años venideros. Esta idea coincidió en poco tiempo con la llegada al poder de gobiernos con la idea de desarrollar una presencia más activa en el ámbito internacional de estos países, como fueron los casos de Lula da Silva en Brasil, Manmohan Singh en India, Thabo Mbeki en Sudáfrica y Hu Jintao en China, además de la consolidación de Vladimir Putin como líder de la Federación Rusa. Es decir, no buscaban un cambio rotundo en el sistema internacional, sino obtener una mayor participación en las esferas de negociación global y ser parte importante en el sistema productivo globalizado. Algunas de las premisas fundamentales del grupo consistían en la conformación de un orden mundial multipolar, buscando ofrecer alternativas al capitalismo financiero y especulativo, y realizar una revisión de las instituciones de gobernanza internacional heredadas de la Guerra Fría y de Bretton Woods (Pelfini, Fulquet y Bidaseca, 2015, p. 9). 
El 2008 fue el año clave para este grupo, ya que fue allí cuando se convirtió en una iniciativa gubernamental, incentivada sin dudas por la crisis financiera internacional de ese mismo año. Un año después se concretó el primer encuentro intergubernamental de los cuatro países BRIC en la ciudad rusa de Ekaterimburgo. En el 2011 se decidió incorporar a Sudáfrica al grupo. Si bien este país tiene atributos de poder incomparables con los otros cuatro, la percepción que tiene del resto de los Estados como la principal potencia del continente la posicionó como un actor clave en las esferas globales de negociación como representante de su continente. De esta forma, los BRICS se han institucionalizado como un foro internacional, que celebra cumbres presidenciales y reuniones ministeriales periódicamente.

Durante sus primeros años, el bloque centró sus demandas en el ámbito financiero, intentando promover una reforma de la arquitectura global, con fuertes críticas a instituciones como el Banco Mundial (BM) y el Fondo Monetario Internacional (FMI). Pero posteriormente se consolidaron como una referencia en cuanto a problemas de envergadura mundial, como los conflictos bélicos en Medio Oriente. También han abogado por la defensa de los valores democráticos, la multietnicidad y la valorización de la figura del Estado, haciendo hincapié en el respeto de la soberanía. Así, estos poderes emergentes se convirtieron en interlocutores válidos y necesarios para el establecimiento del orden internacional vigente a comienzos de siglo (Giaccaglia, 2017).

En esta década donde los BRICS se consolidaron como un grupo de peso dentro de las relaciones internacionales, han conseguido algunos logros importantes en cuanto a su participación en determinadas instituciones de la gobernanza mundial.

En el ámbito comercial, han tenido una destacada participación en la Organización Mundial de Comercio (OMC). En el año 2013 fue elegido Director General de esta institución el brasileño Roberto Azevedo, demostrando la cada vez mayor importancia de los países emergentes en la esfera comercial multilateral. Como destaca la ya citada Giaccaglia: "los Estados miembros de los BRICS se siguen demostrando comprometidos con el logro de una economía global abierta. Reconocen, con todo, que los países tienen diferentes capacidades y se encuentran a diferentes niveles de desarrollo" (2017, p. 443).

Fue en el ámbito financiero donde probablemente mayor impacto tuvieron las acciones de los BRICS. Esto sucedió en buena medida a partir de la crisis del 2008, donde las instituciones de Bretton Woods se mostraron incapaces de sobrellevar la situación. A partir de allí, los BRICS comenzaron a reclamar mayor participación en diferentes organismos. Por una parte, en 2010 en el Banco Mundial consiguieron la modificación de los derechos de voto, obteniendo mayor peso al ser reconocida su creciente importancia en la economía global. Por otro lado, también se concretaron cambios en la estructura del FMI, con su reforma en el año 2015. Así, China se convirtió en el tercer país miembro más grande dentro del organismo, mientras que Brasil, India y Rusia se ubicaron entre sus diez principales accionistas. Por último, vale mencionar que en 2014 los países BRICS crearon el Nuevo Banco de Desarrollo, destinado a proyectos de infraestructura, y pusieron en marcha el Acuerdo de Reservas de Contingencia, para proteger sus monedas.

Otro caso significativo se dio entre los años 2012 y 2013, cuando sus contribuciones al presupuesto de la Organización de las Naciones Unidas se modificaron. China se convirtió en el sexto mayor contribuyente, aumentando su cuota en $61 \%$ (pasando del 3,2 al 5,1\% del presupuesto global de la organización). Por su parte, Brasil incrementó sus cuotas en $82 \%$, para pasar del 1,6 al 2,9\%. Mientras que India también acrecentó sus pagos, aunque solamente en un $24 \%$, determinando una ampliación del 0,5 al 0,66 \% (Morales, 2013).

Si bien podrían mostrarse otros ejemplos relativos al aumento de la consideración de los BRICS en diferentes ámbitos de la gobernanza global, los casos desarrollados previamente dejan en claro que estos países han buscado sentarse en la mesa de los grandes, siguiendo las reglas de juego existentes. Lo que comprueba que son agentes efectivos en la construcción de un orden multipolar, centrándose en realizar ajustes en el sistema internacional. Por su parte, las potencias tradicionales no fueron indiferentes frente al avance de los países emergentes, sino que su política para este sector fue la de permitir su incorporación en los ámbitos de decisión multilaterales, con el propósito de influir e incluso condicionar sus comportamientos, intentando que sean más predecibles y calculables. 


\section{BRASIL COMO PODER EMERGENTE SURAMERICANO}

Este contexto mundial de ascenso de los poderes emergentes también se replicó en América Latina, y particularmente en América del Sur, con la proyección de Brasil como el estandarte de este proceso en la región. Las circunstancias que permitieron a este país consolidarse como tal fueron diversas.

Brasil se encuentra geográficamente dentro de la periferia del sistema económico mundial, con grandes problemas socioeconómicos; incluso es considerado uno de los países más desiguales del planeta. Como todos los países emergentes, ha estado atravesado por dinámicas centralizantes, ya que históricamente se ha vinculado con los grandes centros de poder político y económico mundiales gracias a su enorme dotación de recursos naturales, su territorio y su desarrollo industrial.

El desarrollo industrial de Brasil tiene una larga trayectoria. El sector de la industria liviana se desarrolló desde comienzos del siglo XX alrededor de los centros exportadores de commodities más dinámicos, principalmente en San Pablo, donde se forjó el sector de la burguesía más importante del país. Esta ciudad logró transformar con cierta velocidad su incipiente industria cafetera en un sector industrial diversificado, con todos los tipos de fabricación en su interior. Se consolidó como la gran metrópoli industrial del país, destacándose como centro productor y de distribución primaria hacia el interior, gracias a una red de comunicaciones y de transporte que integraron los diferentes territorios brasileños (Silveira, 2007).

La política exterior del país durante buena parte del siglo XX estuvo determinada por la Doctrina Río Branco, bajo la cual se buscaba fortalecer el panamericanismo, estrechando la relación con los Estados Unidos, ejercer liderazgo en Suramérica y aumentar el prestigio nacional de Brasil en el extranjero (Rocha y Morales, 2008). Esta postura se invirtió en la década de 1980, a partir del proceso de redemocratización del país. Por ejemplo, se buscó fundar una alianza estratégica con Argentina, el segundo mayor país América del Sur. En 1988 se firmó el Tratado de Integración, Cooperación y Desarrollo; mientras que en 1991 se promovió la creación del Mercosur, incorporando también a Uruguay y Paraguay.

En este contexto, la Constitución de 1988, una vez restablecida la democracia en el país, fue de gran importancia en la redefinición de las relaciones entre Estado, mercado y sociedad civil. Desde entonces, Brasil se logró proyectar en el ámbito internacional gracias a sus posicionamientos políticos, una activa política externa y sus atractivos culturales. A partir de sus importantes capacidades duras (económicas y militares) y sus capacidades blandas moderadas (capacidad negociadora de su diplomacia), Brasil consolidó su rol de mediador entre Estados del sistema interamericano, así como también pudo ejercer una hegemonía regional sobre Estados periféricos. Dicha hegemonía regional consiguió llevarla a cabo gracias a su capacidad para desplegar su geoeconomía, su geopolítica y su geoestrategia en el espacio suramericano. En los últimos años de gobierno de Fernando Henrique Cardoso (1995-2003) se comenzó a gestar la política exterior que profundizaría su sucesor Luis Ignacio Lula da Silva, centrada en una distancia sutil con Estados Unidos y la aproximación con sus vecinos suramericanos y otros países periféricos y semiperiféricos a nivel global, principalmente India, China y Sudáfrica (Vadell, Giaccaglia, Morayta y Mabire, 2020).

De esta manera, el salto en la consolidación de Brasil como potencia regional se dio a comienzos del siglo XXI. Durante esos años, el ascenso de China en materia comercial llevó a convertir a este país asiático en uno de los grandes consumidores de materias primas a nivel mundial. Esto generó un notorio crecimiento económico de los países latinoamericanos, basado en la especialización en la producción y exportación de estos productos primarios para el mercado asiático (que aumentaron su valor comercial). Brasil dedica desde entonces buena parte de su exportación hacia China de soja y mineral de hierro. Esto les permitió a los sectores agroexportadores fortalecer su posición como sectores de peso en la toma de decisiones de la política brasileña, relegando progresivamente a los sectores industriales, que se vieron perjudicados por el aumento de las importaciones manufactureras desde China (Pose y Bizzozero, 2019).

La generación de una gran cantidad de divisas hizo que su posición financiera mejorara notablemente. Esto le permitió al principal país de la región plasmar sus intereses geoestratégicos y geopolíticos, para 
consolidarse en su área circundante, pensándose con una proyección global. Así, los Estados latinoamericanos rediseñaron la arquitectura regional de organizaciones internacionales en el Hemisferio Occidental con la creación de nuevas instituciones multilaterales y con la exclusión de Estados Unidos en ellas. Una de las más importantes fue la Unión de Naciones Suramericanas (UNASUR), lanzada oficialmente en 2008. La idea de su conformación se remontaba a 2004, cuando vio la luz la Comunidad de Naciones Suramericanas. La UNASUR fue la expresión multilateral de un interés del presidente Lula da Silva de crear un marco institucional que permitiera a su país convertirse en líder de América del Sur. Como destaca Barrenengoa, en estos procesos

se enfatizaban como aspectos centrales el estímulo a la integración sudamericana en aras de contribuir a la cooperación militar regional, integrar las bases industriales, defender los recursos energéticos luego del descubrimiento de reservas petrolíferas en el litoral atlántico, y llegar al océano Pacífico desde corredores comerciales (2017, p. 8).

La construcción de grandes obras de infraestructura entonces fue una de las grandes misiones de UNASUR, para lo cual se creó el Consejo Suramericano de Infraestructura y Planeamiento (COSIPLAN), que era el encargado de la proyección y gestión de dichas obras, que abarcaban entre otras áreas a hidroeléctricas, corredores bioceánicos, aeropuertos, conexiones viales, interconexiones y corredores ferroviarios, transporte multimodal, construcción de túneles y puentes binacionales, pasos de frontera, gasoductos, rutas, conectividad, etc. Se buscaba conseguir el "aumento del comercio intrarregional, la integración de las cadenas productivas, la inserción en el mercado internacional más competitiva y la contribución al desarrollo sostenible como horizontes" (Barrenengoa, 2017, p. 12). Donde más se intentó focalizar esta política de construcción de grandes obras de infraestructura fue en los corredores bioceánicos, ya que eso les permitiría a los sectores más dinámicos de la economía brasileña mejorar el transporte, y de esa forma el comercio, con el Océano Pacífico, llegando más rápidamente hacia la República Popular China (desde hace algunos años su principal socio comercial). Incluso vale destacar que muchos de estos proyectos estuvieron financiados por Banco Nacional de Desarrollo Económico y Social (BNDES) de Brasil. Lo que demuestra esto es que, como potencia regional, y a través de estos procesos de integración, tanto política, como económico y físicamente (mediante las obras de infraestructura) Brasil, durante los primeros quince años del siglo XXI, se intentó consolidar como el hegemón de la región suramericana, como así también tener un papel destacado en las relaciones internacionales a nivel mundial. En palabras de Morales: "los esfuerzos de esta política exterior han estado orientados para incrementar su poder de negociación como portavoz de la subregión, obtener el reconocimiento internacional de potencia regional e inclinar sutilmente la balanza de poder hacia América Latina." (2013, p. 166).

Pero esta situación comenzó a ser puesta en discusión en los últimos años. Durante la segunda mitad de la segunda década del presente siglo, se sucedieron diversos procesos que marcaron la disminución de la participación de Brasil en el plano internacional, comparándolo con lo explicado previamente. El estancamiento de los BRICS como bloque (en cuanto a su coordinación de políticas comunes), la desaceleración del crecimiento económico chino, que se concentró más en su disputa comercial y tecnológica con Estados Unidos (relegando su participación en conjunto con otras potencias emergentes), y a la disminución de los precios internacionales de las materias primas exportadas por el gigante sudamericano fueron factores externos clave en este declive.

En el ámbito interno, este cambio se dio fundamentalmente a partir del año 2016. Este año marcó la salida del gobierno de la entonces presidenta Dilma Rousseff a través de un proceso de impeachment, y la asunción en su lugar de Michel Temer, quien ejercía la vicepresidencia del país. Además de generar el recambio en el Jefe de Estado, su política exterior también sufrió una marcada variante. Las iniciativas regionales que habían tenido un fuerte impulso años anteriores ya no fueron prioridad. Una muestra clara de ello fue el abandono de UNASUR por parte de Brasil y otros países más del bloque. En su reemplazo durante el 2019 conformaron, por iniciativa de los presidentes de Colombia (Iván Duque) y de Chile (Sebastián Piñera), el Foro para 
el Progreso de América del Sur, conocido popularmente como PROSUR, con una postura marcadamente más cercana a la hegemonía hemisférica estadounidense. Además, se propuso en reiteradas oportunidades flexibilizar el bloque del Mercosur, en un intento por acelerar los tiempos de negociación de acuerdos de libre comercio con terceros países.

La llegada al gobierno de Jair Bolsonaro, a comienzos del año 2019, también generó sus consecuencias en la posición del país como potencia regional. El nuevo presidente tiene una marcada preferencia por la relación con Estados Unidos, colocando entre sus objetivos una alineación automática con la todavía principal potencia mundial, buscando además integrarse de manera unilateral a la economía global (Vadell, Giaccaglia, Morayta y Mabire, 2020). En este sentido, el regionalismo suramericano no aparenta ser un aspecto relevante para la proyección internacional del nuevo gobierno. El propio ministro de Economía, el neoliberal Paulo Guedes, apuntó antes de asumir que "el Mercosur no es prioridad" (Armendáriz, 2018). Más allá de que en declaraciones posteriores corrigió sus dichos, esta frase reconoce que la apuesta de Brasil es por la inserción unilateral a los mercados internacionales. No obstante, hay que destacar que el rumbo que tomará el modelo de desarrollo del país se encuentra disputado entre diferentes sectores del propio gobierno. Por un lado, el presidente Bolsonaro, junto con Guedes y el ministro de Relaciones Exteriores, Ernesto Araujo, representan el ala neoliberal, con vínculos cercanos al sector financiero y a los agronegocios, que como se mencionó previamente fue un sector que se fortaleció a raíz del aumento de los precios de las materias primas exportadas los años anteriores. Son estos sectores los que priorizan la liberalización de la economía, debido a sus ventajas comparativas a nivel global. Por el otro lado, el vicepresidente Hamilton Mourao y la cúpula militar, defienden el Mercosur y los intereses de la burguesía industrial aglutinados en la Confederación de la Industria de Brasil (CNI), para quienes la región presenta el lugar de mayor colocación de sus productos, en un contexto de caída de su peso relativo para la economía nacional. Vale destacar que, como se demuestra en el Gráfico 1, el peso que tiene el sector industrial dentro del producto interno bruto del país revela en los últimos treinta años un marcado retroceso. Para el año 1989, este sector representaba más del $40 \%$ del total de la generación de valor; mientras que, para el 2019, el descenso llegó hasta el $18 \%$. Esta disminución de la industria también permite comprender el interés creciente por liberalizar los vínculos externos del país, ya que es una de las demandas del cada vez más relevante sector agroexportador, que presenta marcadas ventajas comparativas a nivel mundial. 


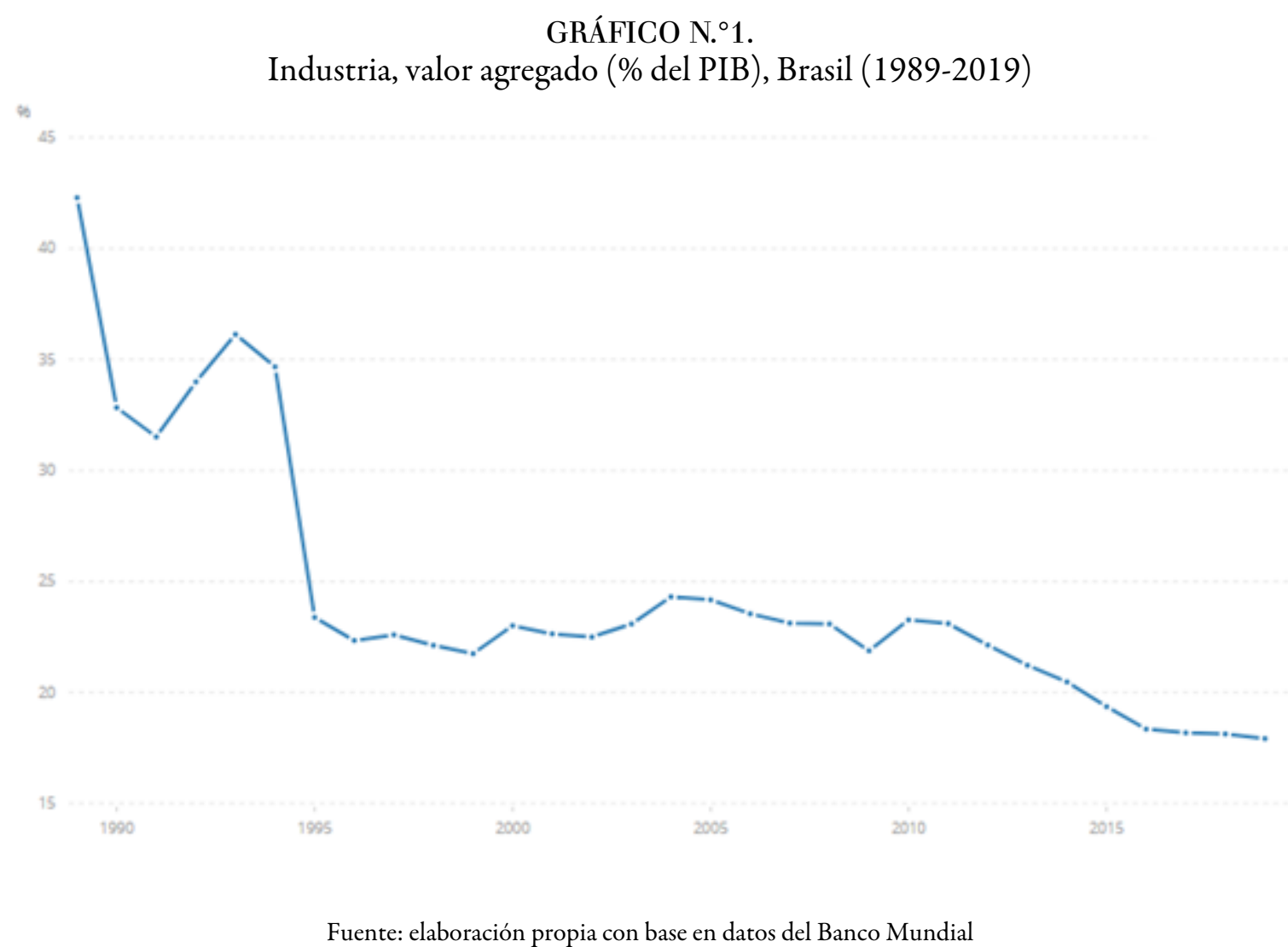

Lo cierto es que el cambio en la tradición de política exterior es notorio. Desde el retorno de la democracia en la década de 1980, Brasil se caracterizó por tener una postura más cercana al autonomismo en el ámbito internacional (con variantes según los diferentes modelos económicos). No es menor destacar que excancilleres de Brasil (entre ellos el también expresidente Fernando Henrique Cardoso) redactaron una carta acusando al gobierno de Bolsonaro de "destruir la credibilidad externa del país y violar disposiciones de la Constitución brasileña sobre política internacional”. (Nejamkis, 2020). A esto se le suma la creciente conflictividad en la relación bilateral con Argentina y el recién asumido Alberto Fernández como presidente del país. Esto muestra que todo el liderazgo que pudo haber ejercido Brasil durante los últimos años se está viendo desvanecido por el cambio de rumbo en su política exterior, su desinterés por fomentar la integración regional, de la cual era su principal patrocinador desde comienzo del siglo XXI.

\section{REFLEXIONES FINALES}

El comienzo del siglo XXI ha marcado un significativo cambio en la geopolítica internacional. Al consenso generalizado de la época posterior al fin de la Guerra Fría, le siguió un contexto de pérdida de la unipolaridad de Estados Unidos como gran potencia global, aunque aún continúa vigente su supremacía en términos militares, tecnológicos, económicos y culturales (discutido cada vez más en los últimos años por el ascenso de China en la escena mundial).

Es destacable la notoriedad que han obtenido los poderes emergentes, fundamentalmente los países que conforman el BRICS, en diferentes ámbitos de la política internacional. A lo largo del presente trabajo se ejemplificó esto con el aumento de su participación en algunos organismos como la OMC, el FMI y la ONU. Lo que vale destacar también es que estos actores emergentes buscaron hacer oír su voz dentro de estas instituciones, sentarse en la mesa de las grandes negociaciones, pero sin pretender generar un cambio sistémico en las relaciones internacionales. 
El caso de Brasil es de gran relevancia para América del Sur, ya que desde la década del ochenta que su política exterior ha estado enfocada en la consolidación de su papel de potencia regional en el subcontinente. La conformación de diferentes entidades de integración ha sido una muestra cabal de esta postura. A comienzos del siglo XXI, a partir de las circunstanciales mejoras económicas, se proyectó ya no sólo como un líder regional, sino también como un jugador en la escena global (no es casualidad que forme parte de los BRICS). Por este motivo han sido tan relevantes los diferentes proyectos dentro de UNASUR, principalmente los que tenían que ver con la construcción de corredores bioceánicos para tener una mejor conectividad con la región de Asia Pacífico. No obstante esta situación, el rol ambivalente de China, que se presenta tanto como parte de los países emergentes, como así también de los ya emergidos, presenta el riesgo de reproducir la trayectoria asimétrica que países como Brasil han tenido históricamente con las potencias centrales. Hasta el momento, estas sociedades emergentes no parecen haber sido lo suficientemente exitosas en sus modelos de desarrollo ya que, en el caso de Brasil, sigue dependiendo de la exportación de productos primarios, como la soja y el hierro, profundizando el neocolonialismo y el extractivismo.

\section{REFERENCIAS}

Armendáriz, A. (28 de octubre de 2018). El Mercosur no será una prioridad del próximo gobierno, advirtió el futuro ministro de Economía. Diario La Nación. Recuperado de: https://www.lanacion.com.ar/el-mundo/el-mercosu r-no-sera-prioridad-del-proximo-nid 2186338

Barrenengoa, A. (2017). Las clases dominantes en la integración suramericana: Estados, actores e intereses en la integración del COSIPLAN-UNASUR. XXXI Congreso ALAS. Montevideo, Uruguay.

Domínguez, J. (2015). Los cambios en el sistema internacional a partir de 2000. Foro Internacional, 220, 391-432.

Giaccaglia, C. (2017). Poderes tradicionales, emergentes y re-emergentes: relaciones ambiguas, pero pragmáticas. Foro Internacional, 228, 422-459.

Morales, D. (2013). En las entrañas de los BRIC: Análisis de la naturaleza semiperiférica de Brasil, Rusia, India y China. Austral: Revista Brasileira de Estratégia e Relaģoes Internacionais, 2(4), 147-181.

Nejamkis, G. (9 de mayo de 2020). Duro ataque contra la política exterior de Jair Bolsonaro: destruyó la credibilidad de Brasil, afirman ex cancilleres. Diario Clarín. Recuperado de: https://www.clarin.com/mundo/duro-ataquepolitica-exterior-jair-bolsonaro-destruyo-credibilidad-brasil-afirman-ex-cancilleres_0_m_oCceJWr.html

Organización Mundial de Comercio (2013). Informe sobre el comercio mundial. Recuperado de: https://www.wto. org/spanish/res_s/booksp_s/world_trade_report13_s.pdf

Pelfini, A., Fulquet, G. y Bidaseca, K. (2015). Introducción. Los BRICS en el orden global: ¿construyendo nuevos cimientos o negociando con las estructuras existentes? En A. Pelfini y G. Fulquet (eds.), Los BRICS en la construcción de la multipolaridad: ¿reforma o adaptación? (pp. 9-18). Buenos Aires: Clacso.

Pose, N., y Bizzozero, L. (2019). Regionalismo, economía política y geopolítica: tensiones y desafíos en la nueva búsqueda de inserción internacional del Mercosur. Revista Uruguaya de Ciencia Politica, 28(1), 249-278.

Rocha, A. y Morales, D. (2008). El sistema político internacional de post Guerra Fría y el rol de las potencias regionales mediadoras. Espiral. Estudios sobre Estado y Sociedad, 15(43), 23-75.

Silveira, M. L. (2007). Diferencias regionales en el territorio brasileño: perspectiva diacrónica y sincrónica. Scripta Nova: revista electrónica de geografía y ciencias sociales. Vol. 11, Núm. 1.

Vadell, J. A., Giaccaglia, C., Morayta, G. C., y Mabire, B. (2020). El rol de Brasil en el regionalismo latinoamericano. Foro Internacional, 60, 3(241), 1041-1080. 